\title{
НАЛОЖЕНИЕ ДВОЙНОГО СПИРАЛЬНОГО НЕПРЕРЫВНОГО ГЕМОСТАТИЧЕСКОГО ШВА ПРИ РЕЗЕКЦИИ ПЕЧЕНИ
}

\author{
(С) Лазаренко В.А., Перьков А.А.
}

\author{
Кафедра хирургических болезней ФПО \\ Курского государственного медицинского университета, Курск \\ E-mail: anperkov@yandex.ru
}

\begin{abstract}
Предложен способ наложения шва при резекции печени, заключающийся в том, что после резекции накладывают двойной спиральный непрерывный гемостатический шов. Способ апробирован в эксперименте на 24 собаках с хорошими результатами. Применение разработанного способа ускоряет наложение шва, обеспечивает надежный гемостаз, позволяет осуществить равномерную компрессию на сосудисто-желчные образования паренхимы печени в зоне манипуляций, значительно уменьшает ишемизированную зону культи печени, лежащую дистальнее швов, минимизирует вероятность развития некроза этой зоны в послеоперационном периоде и уменьшает количество возможных остаточных полостей между раневой поверхностью печени и участком большого сальника, что способствует значительному улучшению результатов операций и снижению послеоперационных осложнений.
\end{abstract}

Ключевые слова: печень, резекция, шов, гемостаз, резекция печени.

\section{APPLYING DOUBLE SPIRAL UNINTERRUPTED HEMOSTATIC SUTURE DURING HEPATIC RESECTION Lazarenko V.A., Perkov A.A.}

Department of Surgery of FPE of Kursk State Medical University, Kursk

The new method of applying a suture during hepatic resection was developed. It consists in applying a double spiral uninterrupted hemostatic suture after resection. The method approved in the 24 dogs experiment revealed good results. The application of the technique developed accelerates suturing, provides a reliable hemostasis, ensures uniform compression on the vascular and bile formations of liver parenchyma at the manipulation area, and significantly reduces the ischemic area of the liver stump, which lies distal to sutures. It minimizes the chance of postoperative necrosis of this area and reduces the number of possible residual cavities between the wound surface of the liver and epiploon portion. It contributes to far more successful surgical results with minimum postoperative complications.

Keywords: liver, resection, suture, hemostasis, hepatic resection.

В настоящее время хирургия печени достигла больших успехов. Однако несмотря на значительный прогресс в хирургической гепатологии, остался еще ряд проблем, ждущих своего решения. Одной из них является обработка раневой поверхности при резекции органа. Именно от совершенства методики и техники обработки культи печени зависят те или иные из типичных осложнений в послеоперационном периоде [1, 6].

Зачастую при операциях на печени в качестве основного способа окончательной остановки кровотечения используются гемостатические швы в различных модификациях [5]. Большинство из них отличается сложностью выполнения и не обеспечивает надежного гемо- и холестаза вследствие недостаточной герметичности из-за неравномерной компрессии сосудисто-желчных образований, прорезывания паренхимы печени в зоне манипуляций с угрозой развития вторичного кровотечения [2, 3]. Для многих из известных швов характерны значительные затраты времени на их наложение, что в конечном итоге увеличивает продолжительность операции. Вопрос технической оптимизации сегодня остается весьма актуальным и практически важным, поэтому поиск более надежных и совершенных гемостатических швов продолжается.

С целью упрощения техники, сокращения времени операции и обеспечения надежного гемостаза, и, как следствие, снижения числа послеоперационных осложнений, возникающих в зоне культи печени после ее резекции, нами разработан новый «Способ наложения двойного спирального непрерывного гемостатического печеночного шва» (получен патент на изобретение № 2566213) [4].

\section{МАТЕРИАЛЬ И МЕТОДЫ ИССЛЕДОВАНИЯ}

Было проведено экспериментальное исследование на 24 собаках, оно состояло из двух групп опытов. Экспериментальных животных наблюдали до 30 суток включительно, у них производили забор крови из бедренной вены для биохимических исследований и пункционную биопсию печени для определения содержания продуктов перекисного окисления липидов 
(ПОЛ) в гомогенате ткани печени. Индикаторами синдрома цитолиза являлись активность АЛТ и АСТ. Показателями синдрома холестаза - активность щелочной фосфатазы, концентрация билирубина, холестерина и $\beta$-липопротеидов. Индиикаторами гепатодепрессивного синдрома служили концентрация общего белка, содержание фибриногена и протромбиновый индекс; мезенхимально-воспалительного синдрома - тимоловая проба. Содержание продуктов ПОЛ - диеновых конъюгатов (ДК) и малонового диальдегида (МДА) - определяли по методу И.Д. Стальной с соавт. (1977). У всех животных перед началом экспериментов производили забор крови из вены бедра для биохимических исследований (контроль). В день эксперимента брали биохимические анализы до премедикации перед операцией и через 30 минут после нее.

В первой группе экспериментальное исследование было выполнено на 18 собаках. Все оперативные вмешательства выполнялись из верхнесрединного лапаротомного доступа под внутривенным гексеналовым наркозом. Препарат вводился из расчета 30 мг/кг веса животного. Премедикация производилась атропином 0,1 мл $0,1 \%$ раствора и димедролом 0,2 мл $1 \%$ раствора, которые вводили внутримышечно за 30 минут до операции. Помимо того, у всех животных проводилась инфузионная терапия 5\% раствором глюкозы и физиологическим раствором в объеме от 150 до 250 мл. Резекция левой наружной доли печени с наложением двойного спирального непрерывного гемостатического печеночного шва по предлагаемому нами способу (рис. 1) осуществлялась следующим образом. После обработки операционного поля $1 \%$ раствором хлоргексидина биглюконата производили верхнесрединную лапаротомию. Производили перевязку элементов глиссоновой и кавальной систем левой наружной доли печени. После этого пересекалась левая треугольная связка с последующим отделением левой наружной доли печени тупым и острым путем по междолевой борозде и на культю оставшейся части печени накладывали эластический зажим. Полностью удаляли левую долю печени и производили дополнительный гемостаз на крупных сосудистожелчных образованиях, хорошо видимых на раневой поверхности культи печени (1), которые нами прошивались и перевязывались лавсаном. Затем накладывали двойной спиральный непрерывный гемостатический шов со стороны раневой поверхности печени, производя вкол иглой в углу раны ближе к срединной продольной оси раны с выколом на диафрагмальной поверхности печени, отступя от края на 1 см, после чего производили вкол иглой с этой же нитью на срединной продольной оси раны и выкол на диафрагмальной поверхности печени. И так до противоположного угла раны, где через толщу паренхимы переходили на висцеральную поверхность печени, производя там выкол иглы. Отсюда переводили нить на диафрагмальную поверхность, где, отступя от края на 1 см, делали вкол иглой, проходя сквозь всю толщу паренхимы от диафрагмальной до висцеральной поверхности и продолжали наложение шва в такой же последовательности, теперь уже прошивая всю толщу паренхимы, продвигаясь к углу раны, с которого начиналось наложение шва.

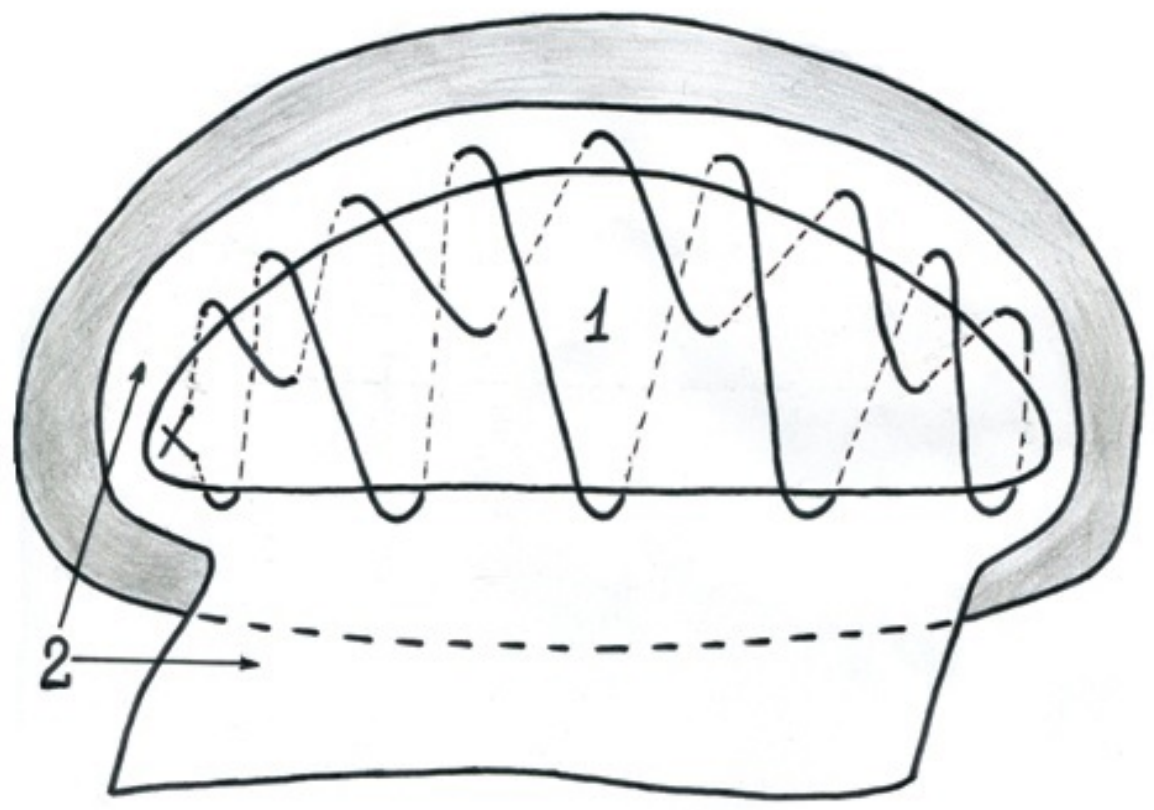

Рис. 1. Вид культи печени с наложенным двойным спиральным непрерывным гемостатическим печеночным швом: 1 - культя печени; 2 - участок большого сальника. 
Для завершения наложения шва после выкола на висцеральной поверхности печени снова рядом делали вкол с выколом на раневой поверхности неподалеку от точки начала шва. После этого оба свободных конца нити связывали между собой со стороны раневой поверхности, тем самым также производя компрессию паренхимы. Каждый раз иглу вкалывали с таким расчетом, чтобы она вышла на поверхности печени, отступя от края раны на 1 см и постоянно смещаясь в сторону наложения шва. Для удобства в процессе наложения шва после выкола на любой из поверхностей на нить временно накладывали зажим для предупреждения ослабевания натяжения нити; по ходу наложения шва этот зажим перекладывали. После этого участком большого сальника (2) на ножке окутывали раневую поверхность культи печени, при этом натягивая сальник по всей площади раневой поверхности печени до полного соприкосновения c ней c заходом на верхнюю и нижнюю поверхности печени. Сальник подшивали узловыми швами. Затем производили контроль гемостаза и послеоперационную рану брюшной полости послойно зашивали наглухо. Кровопотеря непосредственно во время резекции составляла не более $30 \pm 5$ мл. Оперированные животные наблюдались в течение 30 суток.

Вторая группа животных (6 собак) была нами использована для изучения восстановительных процессов в зоне раневой поверхности после резекции левой наружной доли печени с наложением двойного спирального непрерывного гемостатического печеночного шва по нашему способу. В данной группе также определялись биохимические показатели сыворотки крови. Животные выводились из опыта в день операции и на 1, 3, 7, 14 и 30-е сутки. По вскрытии брюшной полости визуально оценивалось как ее состояние в целом, так и в зоне операции. Также забирались кусочки тканей для патоморфологических исследований. В этой группе экспериментов мы изучали процессы перекисного окисления липидов - индикатора степени выраженности поражения клеточных мембран гепатоцитов. Для этого нами определялось содержание первичных (диеновые конъюгаты) и вторичных (малоновый диальдегид) продуктов ПОЛ в гомогенате ткани печени после операции на тех же сроках, что и биохимические показатели сыворотки крови.

Для проверки надежности гемостаза при наложении двойного спирального непрерывного гемостатического печеночного шва мы также использовали органокомплексы (печень, диафрагма, желудок, двенадцатиперстная кишка, тонкий, толстый кишечник и большой сальник) тру- пов людей, смерть которых не была связана с заболеваниями органов брюшной полости. На 11 органокомплексах мы выполнили 11 левосторонних гемигепатэктомий (преимущественно резецировали II, III и IV сегменты) с наложением двойного спирального непрерывного гемостатического печеночного шва. Перед операцией, выполняемой на органокомплексе, для проверки полноты гемостаза производили раздельное канюлирование билиарной и сосудистых систем печени (артериальной и венозной) по методике И.А. Буракова (1979 г.) (устройство, состоящее из аппарата Боброва и манометра). Через канюли нагнетались красители под давлениями, равными прижизненным давлениям в каждой из систем печени. О степени гемостаза можно было судить по появлению капелек окрашенных жидкостей на раневой поверхности печени.

Статистический анализ результатов исследования производили с помощью компьютерной программы статистической обработки данных путем вычисления средних арифметических (M) и средних ошибок средних (m). Оценка достоверности различия средних значений производили с помощью параметрического t-критерия Стьюдента. Различия между группами считались статистически значимыми при уровне $\mathrm{p}<0,05$.

\section{РЕЗУЛЬТАТЫ ИССЛЕДОВАНИЯ И ИХ ОБСУЖДЕНИЕ}

В первой группе животных послеоперационный период у всех животных протекал удовлетворительно. Все животные после операции выжили. Контрольные биохимические показатели были следующими: АЛТ - 0,76 \pm 0,05 ммоль/(ч·л); АСТ - 0,48 \pm 0,09 ммоль/(ч·л); билирубин - 13,51 \pm 0,16 мкмоль/л; щелочная фосфатаза - 2,37 \pm 0,24 ммоль/(ч·л); холестерин - 3,89 \pm 0,35 ммоль/л; $\beta$-липопротеиды - 0,31 \pm 0,06 г/л; фибриноген $-3,91 \pm 0,12$ мг/л; ПТИ $-82,3 \pm$ $1,94 \%$; общий белок - 71,4 $\pm 1,17$ г/л; мочевина $3,78 \pm 0,25$ ммоль/л; тимоловая проба $-1,46 \pm$ 0,06 ед. При оценке динамики изменения биохимических показателей в ходе эксперимента обращает на себя внимание, что наблюдалось не очень выраженное развитие цитолитического синдрома и в меньшей степени холестатического и гепатодепрессивного синдромов. Наши исследования показали, что у экспериментальных животных в день операции отмечалось повышение активности трансаминаз, билирубина (таблица 1), причем максимальные значения этих показателей наблюдались на третьи сутки: АЛТ и АСТ повышались соответственно в 4,0 и 3,9 раза, билирубин - в 1,7 раза по сравнению с контрольными данными. Затем они постепенно 
снижались, и полностью эти параметры нормализовались к 30-м суткам после операции. Нами также отмечено небольшое снижение фибриногена, ПТИ, общего белка и повышение содержания мочевины в течение первых трех суток после операции с полным восстановлением к 14-м суткам. Достоверных изменений концентраций холестерина, $\beta$-липопротеидов, щелочной фосфатазы, тимоловой пробы не отмечалось на всех сроках наблюдения.

Во второй группе животных биохимические показатели сыворотки крови оказались сопоставимы с результатами, полученными в первой группе. Анализ содержания диеновых конъюгатов и малонового диальдегида в гомогенате ткани печени (таблица 2) показал, что максимальный подъем этих показателей наблюдался на третьи сутки после операции: ДК повышались в 1,5 раза, а МДА в 1,9 раза по сравнению с нормой. Через две недели отмечалось значительное снижение этих показателей с нормализацией к тридцатым суткам. На всех сроках наблюдения патологического выпота в брюшной полости не было. Париетальная и висцеральная брюшина оставалась гладкой и блестящей, большой сальник хорошо укрывал культю печени. Если на ранних сроках наблюдения (до 7 суток) он еще рыхло спаян с поверхностью культи печени, то на более поздних сроках наблюдения, как микроскопически, так и макроскопически, отмечается постепенное образование хорошо выраженного соединительнотканного рубца, плотно укрывающего культю органа, а в большом сальнике, прилежащем к ней наблюдаются крупные кровеносные сосуды. Значительных циркуляторных расстройств не наблюдается, регенерация оставшегося органа после операции на фоне отмеченных морфологических изменений протекает достаточно интенсивно в зоне повреждения путем митотического деления клеток. В значительно меньшей степени имеет место пролиферация соединительной ткани, что в конечном итоге не нарушает правильного строения новообразованных печеночных долек.

В ходе экспериментов на органокомплексах после наложения швов на культю печени появления красителей под большим сальником, находящимся на раневой поверхности культи, мы не отмечали.

Таблица 1

Динамика изменения биохимических показателей в послеоперационном периоде (M \pm m)

\begin{tabular}{|l|c|c|c|c|c|c|}
\hline \multirow{2}{*}{$\begin{array}{c}\text { Биохимические } \\
\text { показатели }\end{array}$} & $\begin{array}{c}\text { День } \\
\text { операции }\end{array}$ & 1 & 3 & 7 & 14 & 30 \\
\hline АЛТ & $1,37 \pm 0,11$ & $2,86 \pm 0,14$ & $3,04 \pm 0,18$ & $2,67 \pm 0,12$ & $1,29 \pm 0,08$ & $0,77 \pm 0,05$ \\
\hline АСТ & $0,97 \pm 0,09$ & $1,5 \pm 0,12$ & $1,89 \pm 0,26$ & $1,36 \pm 0,07$ & $0,82 \pm 0,04$ & $0,45 \pm 0,06$ \\
\hline Билирубин & $15,73 \pm 0,64$ & $21,35 \pm 0,81$ & $23,14 \pm 1,16$ & $17,46 \pm 0,93$ & $15,02 \pm 0,75$ & $13,71 \pm 1,03$ \\
\hline $\begin{array}{l}\text { Щелочная } \\
\text { фосфатаза }\end{array}$ & $2,63 \pm 0,57$ & $2,92 \pm 0,49$ & $2,85 \pm 0,72$ & $2,59 \pm 0,18$ & $2,57 \pm 0,63$ & $2,45 \pm 0,27$ \\
\hline Холестерин & $3,89 \pm 0,46$ & $3,83 \pm 0,74$ & $3,81 \pm 0,52$ & $3,84 \pm 1,05$ & $3,89 \pm 0,92$ & $3,93 \pm 0,79$ \\
\hline$\beta$-липопротеиды & $0,33 \pm 0,19$ & $0,35 \pm 0,66$ & $0,37 \pm 0,47$ & $0,30 \pm 0,64$ & $0,31 \pm 0,73$ & $0,32 \pm 0,58$ \\
\hline Фибриноген & $3,14 \pm 0,17$ & $3,02 \pm 0,36$ & $3,29 \pm 0,14$ & $3,47 \pm 0,23$ & $3,84 \pm 0,18$ & $3,86 \pm 0,19$ \\
\hline ПТИ & $80,6 \pm 2,43$ & $70,83 \pm 1,27$ & $70,04 \pm 1,69$ & $78,7 \pm 2,04$ & $83,0 \pm 1,85$ & $82,4 \pm 1,73$ \\
\hline Общий белок & $68,8 \pm 2,15$ & $62,6 \pm 1,03$ & $62,4 \pm 1,36$ & $68,5 \pm 1,12$ & $70,4 \pm 1,84$ & $71,9 \pm 1,57$ \\
\hline Мочевина & $3,92 \pm 0,46$ & $4,27 \pm 0,19$ & $4,86 \pm 0,27$ & $4,07 \pm 0,18$ & $3,83 \pm 0,36$ & $3,81 \pm 0,22$ \\
\hline Тимоловая проба & $1,36 \pm 0,06$ & $1,44 \pm 0,08$ & $1,47 \pm 0,04$ & $1,41 \pm 0,07$ & $1,40 \pm 0,05$ & $1,41 \pm 0,09$ \\
\hline
\end{tabular}

Примечание: единицы измерения: АЛТ и АСТ - ммоль/(ч • л), билирубин - мкмоль/л, щелочная фосфатаза - ммоль/(ч $\cdot$ л), холестерин - ммоль/л, $\beta$-липопротеиды - г/л, фибриноген - мг/л, ПТИ - \%, общий белок - г/л, мочевина - ммоль/л; тимоловая проба - ед; $\mathrm{n}=24$.

Таблица 2

Динамика изменения содержания продуктов ПОЛ в гомогенате ткани печени после операции (M $\pm \mathrm{m})$

\begin{tabular}{|c|c|c|c|c|c|c|}
\hline \multirow{2}{*}{$\begin{array}{c}\text { Продукты } \\
\text { ПОЛ }\end{array}$} & $\begin{array}{c}\text { День } \\
\text { операции }\end{array}$ & 1 & 3 & 7 & 14 & 30 \\
\hline ДК & $1,14 \pm 0,089$ & $1,27 \pm 0,075$ & $1,34 \pm 0,096$ & $1,25 \pm 0,092$ & $1,04 \pm 0,090$ & $0,86 \pm 0,079$ \\
\hline МДА & $0,104 \pm 0,006$ & $0,128 \pm 0,009$ & $0,131 \pm 0,011$ & $0,108 \pm 0,007$ & $0,091 \pm 0,04$ & $0,074 \pm 0,010$ \\
\hline
\end{tabular}

Примечание: единицы измерения: ДК и МДА - ммоль/г; $\mathrm{n}=24$. 
Кроме того, мы выяснили, что шов оставался герметичным не только при нормальном давлении в системе воротной вены, но и при повышении его до 130 - 140 см вод. ст.

Полученные нами позитивные результаты исследований, благоприятное течение послеоперационного периода, умеренные изменения биохимических показателей индикаторов синдромов поражения печени и их преходящий характер свидетельствуют о том, что оперативное вмешательство не только не приводило к необратимым последствиям, но и не оказывало значительного отрицательного воздействия на морфофункциональное состояние печени и организм в целом, что, в свою очередь, подтверждает эффективность использованного нами способа.

Таким образом, можно отметить, что разработанный нами способ наложения двойного спирального непрерывного гемостатического печеночного шва является эффективным, позволяет осуществить равномерную компрессию на сосудисто-желчные образования паренхимы печени в зоне манипуляций, значительно уменьшает ишемизированную зону культи печени, лежащую дистальнее швов, минимизирует вероятность развития некроза этой зоны в послеоперационном периоде и уменьшает количество возможных остаточных полостей между раневой поверхностью печени и сальником. В свою очередь, укрытие раневой поверхности печени участком большого сальника на ножке является хорошим, биологически адекватным, удобным способом перитонизации культи этого органа. Неизолированный сальник обладает благоприятными пластическими свойствами, не угнетает пролиферацию печеночной ткани, не поддерживает воспалительной реакции, не приводит к образованию капсулы и грубого соединительнотканного рубца в зоне повреждения органа. Одним из положительных моментов является также значительное увеличение скорости наложения шва по сравнению со многими печеночными швами, что в условиях ограниченного времени, учитывая простоту наложения шва и его хорошие характеристики, может иметь решающее значение. В результате применения двойного спирального непрерывного гемостатического печеночного шва обеспечивается надежный гемостаз по ходу шва с повышением качества его наложения, а также между элементами шва внутри толщи паренхимы, упрощение техники наложения шва с сокращением необходимого для этого времени, уменьшение возможных послеоперационных осложнений в зоне культи печени после ее резекции.

\section{ЛИТЕРАТУРА}

1. Альперович Б.И. Хирургия печени и желчных путей. - Томск: изд-во ТГУ, 1997. - 605 с.

2. Егиев В.Н.. Буянов В.М., Удотов О.А. Хирургический шов. - М. : Медпрактика-М, 2001. - C. 66.

3. Мильков Б.О., Шамрей Г.П., Полянский И.Ю. Соединение тканей в хирургии: практич. рук-во Черновцы, 1992. - С. 112.

4. Способ наложения двойного спирального непрерывного гемостатического печеночного шва: заявка № 2014152368/14 РФ, МПК А61В 17/04 / Перьков А.А., Лазаренко В.А., Лазаренко С.В. № $2566213 \mathrm{C}$; ; заявлено 23.12.2014; опубл. 20.10 .2015 , Бюл. № 29. -8 с.

5. Шапкин Ю.Г., Чальљ Ю.В., Чалык Р.Ю. Метод ушивания ран печени // Анналы хирургической гепатологии. - 2005 - Т. 10, № 2. - С. 170-171.

6. Kokevling F., Schwartz S.I. Liver surgery. - GmbH, 2001. -232 p. 